\title{
Abdominal Aort Anevrizmalarının Konvensiyonel ve Endovasküler Tamir Sonuçlarının Karşılaştırılması
}

\author{
Görkem ÇİTOĞLU ${ }^{1}$, Enver DAYIOĞLU ${ }^{2}$ \\ 1 Bursa Uludağ Üniversitesi Tıp Fakültesi, Kalp ve Damar Cerrahisi Anabilim Dalı, Bursa. \\ 2 İstanbul Üniversitesi İstanbul Tıp Fakültesi, Kalp ve Damar Cerrahisi Anabilim Dalı, İstanbul.
}

\section{ÖZET}

$\mathrm{Bu}$ araştırmada abdominal aort anevrizmalı (AAA) hastalarda, açı cerrahinin ve endovasküler anevrizma tamirinin (EVAR) erken dönem (ilk 30 gün) sonuçlarının, eşlik eden ek hastalıkların ve risk faktörlerinin retrospektif olarak karşılaştırılması amaçlanmıştır. Merkezimizde Ocak 2002-Aralık 2014 tarihleri arasında non-rüptüre AAA (çap >5cm) sebebiyle, elektif olarak opere edilen 50 hasta incelendi. Hastalar iki gruba ayrıldı; EVAR grubu $(\mathrm{n}=31)$ ve açık cerrahi grubu $(\mathrm{n}=19)$. Demografik bilgiler (yaş, cinsiyet), semptom (karın ağrısı), risk faktörleri (sigara, hipertansiyon, koroner arter hastalığı, kronik böbrek yetmezliği, diabetes mellitus), anevrizma çapı, hastanede ve yoğun bakımda kalış süresi, kan transfüzyonu miktarı, komplikasyon ve mortalite oranları ile ilgili veriler incelendi. Hastaların cinsiyeti büyük oranda (\%94) erkekti. EVAR grubunda kan transfüzyonu miktarı, hastanede ve yoğun bakımda yatış süresi daha düşük saptandı ( $<0,05)$. Bu araştırmaya dayanarak şunu söyleyebiliriz ki; yüksek riskli hastalarda EVAR tercih edilmelidir.

Anahtar Kelimeler: Abdominal aort anevrizması. Açı cerrahi. Endovasküler anevrizma tamiri.

Comparision on Outcomes in Conventional and Endovascular Repair of Abdominal Aortic Aneurysms

\begin{abstract}
In this research, we aimed to compare retrospectively; early (first 30 days) outcomes, additional diseases and risk factors of the patients with abdominal aortic aneurysm (AAA), who underwent endovascular aneurysm repair (EVAR) or open surgical repair. From January 2002 through December 2014, we reviewed 50 patients with unruptured AAA $(>5 \mathrm{~cm}$ in diameter) who were electively treated at our center. Patients were divided into two groups; EVAR group $(\mathrm{n}=31)$ and open surgery group $(\mathrm{n}=19)$. Data about; demographic information (age, sex), symptom (abdominal pain), risk factors (smoking, hypertension, coronary artery disease, chronic kidney disease, diabetes mellitus), diameter of aneurysm, duration of intensive care unit and hospital stay, amount of blood transfusion, complication and mortality rates were analyzed. Sex of the patients were mostly (94\%) male. EVAR group had lower ratios with respect to amount of blood transfusion, length of stay in intensive care unit and hospital $(\mathrm{p}<0,05)$. On the basis of this research we can say that; EVAR should be preferred for high risk patients.
\end{abstract}

Key Words: Abdominal aortic aneurysm. Endovascular aneurysm repair. Open surgery.

Abdominal aort anevrizması (AAA), infradiyafragmatik aortun herhangi bir segmentinin, normal yapısını kaybetmesiyle meydana gelen damar duvarında lokalize zayıflık ile karakterize olan, kişinin yaşına ve vücut yüzeyine göre olması gereken aortik transvers çapın en az 1,5 kat artmış olduğu, dilatasyon ile ken-

Geliş Tarihi: 26.Şubat.2020

Kabul Tarihi: 07.Ekim.2020

Dr. Görkem ÇiTOĞLU

Bursa Uludağ Üniversitesi Tıp Fakültesi,

Kalp ve Damar Cerrahisi Anabilim Dalı,

Bursa.

Tel: 05326342020

E-posta: gorkem06@hotmail.com

Yazarların ORCID ID Bilgisi:

Görkem ÇiTOĞLU: 0000-0001-5316-9166

Enver DAYIOĞLU: 0000-0003-2675-0048 dini gösteren, geri dönüşümsüz, ilerleyici ve dejeneratif bir hastalıktır ${ }^{1}$. Patofizyolojisinde aterosklerotik değişiklikler, media tabakasında elastin ve kollajen dejenerasyonu ve adventisial kalınlaşma rol oynar ${ }^{2}$. AAA prevalansı 65 yaşındaki erkeklerde \%1,34'tür ${ }^{3}$. AAA'da yıllık rüptür riski 5,5-5,9 cm aralığında $\% 9,4$ iken $6,0-6,9 \mathrm{~cm}$ aralığında $\% 10,2$ olup $\geq 7 \mathrm{~cm}$ de ise bu oran \%32,5 saptanmıştır ${ }^{4}$. Radyolojik olarak direkt grafi, ultrasonografi (USG), abdominal bilgisayarlı tomografi (BT) anjiografi, manyetik rezonans görüntüleme ve konvansiyonel anjiografi ya da dijital substraksiyon anjiografi tetkikleri ile anevrizma tespit edilebilir. BT altın standart olarak kabul görmüştür. Endovasküler anevrizma tamiri (EVAR) uygulanacak hastalarda işlem öncesi görüntüleme varyatif anatominin, anevrizma boynunun, greftin tutunma bölgelerinin, femoroiliak ve aksiller vasküler girişim yerlerinin değerlendirilmesinde gerekli olup hasta uygunluğu 


\section{G. Çitoğlu ve E. Dayığlu}

için birçok kriter belirlenmiştir ${ }^{5}$. Aortik anevrizma onarımının nihai hedefi, anevrizma kesesinin dolaşımdan tamamen dışlanması ve zayıflamış aort duvarı üzerindeki basıncın ortadan kaldırılarak, aortik rüptürün engellenmesidir. Abdominal aort çapının $55 \mathrm{~mm}$ 'den büyük olması, çapın $50-55 \mathrm{~mm}$ aralığında olduğu hastalarda ise anevrizma çap artış oranının $>1 \mathrm{~cm} / \mathrm{y}$ 1l ya da hastanın semptomatik olması girişim için endikasyon oluşturmaktadır ${ }^{6}$. EVAR için genelde transfemoral yol kullanılır ve endovasküler greft, küçük bir insizyondan kılavuz tel yardımıyla anevrizma içerisine ilerletilerek, önce proksimalde sonra distalde sağlam bölgeye yerleştirilir. EVAR sonras greft çevresindeki anevrizma kesesi içerisine kan akımının devam etmesiyle olan kaçaklara endoleak denir ve en sık karşılaşılan komplikasyondur ${ }^{7}$. EVAR sonrası hastaların 1/3'ünde görülür fakat bunların yaklaşık yarısı kendiliğinden kaybolur ${ }^{8}$. Endovasküler tedavinin kontrast madde nefrotoksisitesi, greftle ilgili mekanik sorunlar ve greftte tromboz gibi kendine özgü komplikasyonları bulunmaktadır. AAA'da açık cerrahi, laporotomiyi takiben transabdominal ya da retroperitoneal yaklaşımla anevrizma kesesi açıldıktan sonra, greftin proksimalde ve distalde sağlam bölgeye anastomoz edilmesiyle yapılır. Kan kayb1, yoğun bakımda ve hastanede kalış süresi bakımından retroperitoneal yaklaşım transabdominal yaklaşımdan üstün bulunmuştur? ${ }^{9}$.

$\mathrm{Bu}$ araştırmada müdahale gereği doğan non-rüptüre infrarenal abdominal aort anevrizması bulunan hastalarda, açık cerrahinin ve endovasküler greft uygulamasının erken dönem (ilk 30 gün) sonuçlarının, morbidite ve mortalite oranlarının, eşlik eden ek hastalıların ve risk faktörlerinin retrospektif olarak karşılaştırılması amaçlanmıştır. Böylelikle mevcut hasta profilinin tedavisinde, hangi yaklaşımın üstün olduğunu belirlemek, ayrıca hangi ek hastalıkların ve risk faktörlerinin sıklıkla hastalara eşlik ettiğini belirleyip, hastalığın nedenlerinin tespitine ve koruyucu hekimliğe katkıda bulunulmaya çalışılmıştır.

\section{Gereç ve Yöntem}

Araştırmamızda, İstanbul Üniversitesi İstanbul Tıp Fakültesi'nde 2002 Ocak - 2014 Aralık tarihleri arasinda elektif olarak müdahale gereği doğan ve nonrüptüre $5 \mathrm{~cm}$ 'den büyük infrarenal AAA'sı bulunan, 50 hasta retrospektif olarak incelenmiştir. Hastalar EVAR ve açık cerrahi uygulanan gruplar olmak üzere ikiye ayrılmıştır. 31 hastaya EVAR, 19 hastaya ise açık cerrahi uygulanmıştır. EVAR yapılan tüm hastalara kasık insizyonu yapılmıss ve femoral arter yolu ile greft yerleştirilmiştir. Açık cerrahi yapılan tüm hastalara medyan laporotomiyi takiben transabdominal metodla yaklaşılıp anevrizma kesesi açıldıktan sonra greft interpozisyonu yapılmıştır. Erken dönemde (ilk 30 gün) hastaların demografik bilgileri, semptomatik olması (karın ağrısı), risk faktörleri, anevrizma çap1, hastanede ve yoğun bakımda kalış süreleri, kan transfüzyonu miktarı, komplikasyon ve mortalite oranları karşılaştırılmıştır. İncelenen demografik bilgiler yaş ve cinsiyet idi. İncelenen risk faktörleri; sigara kullanımı, DM (diabetes mellitus), HT (hipertansiyon), $\mathrm{KAH}$ (koroner arter hastalığı) ve KBY (kronik böbrek yetmezliği) idi. İncelenen hastalarda gelişen komplikasyonlar; MI (miyokard infarktüsü), ABY (akut böbrek yetmezliği), pnömoni ve atrial fibrilasyon (AF) idi. Araştırmamızda bu sayılan hastalıklardan herhangi birinin operasyon sonrasında görülmesi, o hasta için komplikasyon müspet olarak kabul edilmiştir. Araştırmamız için ilgili etik kuruldan onay alındı.

\section{Istatistiksel Analiz}

Araştırmanın istatistiksel analizleri Statistical Package for the Social Sciences (Windows için SPSS, versiyon 22.0, Armonk, NY: IBM Corp.) programı kullanılarak yapılmıştır. Öncelikle toplanan verilerin belirlenen sınırlar içinde olup olmadığı ve hatalar barındırıp barındırmadıkları kontrol edilmiştir. Daha sonra, kategorik değişkenlerin frekans ve yüzde dağılımları, sürekli değişkenlerin ise aritmetik ortalamaları ve standart sapma değerleri hesaplanmıştır. Son olarak gruplar arası farkların tespitine yönelik olarak, sürekli değişkenler için Mann-Whitney U testi yapılmış, kategorik (kesintili) değişkenler için ise Ki-kare testi yapılmıştır. Anlamlılık değeri 0,05'ten küçük $(\mathrm{p}<0,05)$ bulunduğunda, gruplar arasındaki faklılıklar anlamlı olarak kabul edilmiştir.

\section{Bulgular}

\section{Demografik Veriler}

Ortalama yaş, EVAR grubunda $71,8 \pm 8,3$ y1l, açık cerrahi grubunda $67,8 \pm 8,7$ yil olup, toplamda ise 70,3 $\pm 8,6$ yıl olarak tespit edildi. Erkek hasta sayıs1, EVAR grubunda $29(\% 93,5)$, açık cerrahi grubunda $18(\% 94,7)$, toplamda $47(\% 94)$ olarak saptand1. Ortalama anevrizma çapı, EVAR grubunda $6,69 \pm 1,27 \mathrm{~cm}$, açık cerrahi grubunda 7,26 $\pm 1,84 \mathrm{~cm}$, toplamda ise $6,9 \pm 1,5 \mathrm{~cm}$ olarak tespit edildi. EVAR grubundaki 25 $(\% 80,6)$ hastanın, açık cerrahi grubundaki $13(\% 68,4)$ hastanın, toplamda ise $38(\% 76)$ hastanın işlem öncesi karın ağrısı mevcut idi.

EVAR ve açık cerrahi uygulanan hasta grupları karş1laştırıldığında demografik veriler açısından istatistiksel olarak anlamlı fark saptanmadı $(\mathrm{p}>0,05)$.

\section{Risk Faktörleri}

DM, EVAR grubunda $7(\% 22,6)$, açık cerrahi grubunda $1(\% 5,3)$, toplamda $8(\% 16)$ hastada saptand. HT, EVAR grubunda $19(\% 61,3)$, açık cerrahi grubunda 8 ( \%42,1), toplamda 27 (\%54) hastada tespit edildi. 


\section{Abdominal Aort Anevrizmalarının Tamir Sonuçları}

Sigara kullanan hasta sayıs1, EVAR grubunda $12(\%$ $38,7)$, açık cerrahi grubunda $7(\% 36,8)$, toplamda 19 (\%38) idi. KAH, EVAR grubunda $15(\% 48,4)$, açık cerrahi grubunda $7(\% 36,8)$, toplamda 22 (\%44) hastada mevcut idi. KBY, EVAR grubunda $5(\% 16,1)$, açık cerrahi grubunda $1(\% 5,3)$, toplamda $6(\% 12)$ hastada mevcut idi.

EVAR ve açık cerrahi uygulanan hasta grupları karşılaştırıldığında risk faktörleri açısından istatistiksel olarak anlamlı fark saptanmadı ( $\mathrm{p}>0,05$, Tablo I).

Tablo I. Demografik veriler ve risk faktörleri

\begin{tabular}{|l|c|c|c|c|}
\hline & $\begin{array}{c}\text { EVAR } \\
(\mathbf{n = 3 1})\end{array}$ & $\begin{array}{c}\text { Açık cerra- } \\
\text { hi (n=19) }\end{array}$ & P değeri & $\begin{array}{c}\text { Toplam } \\
(\mathrm{n}=50)\end{array}$ \\
\hline Yaş & $71,8 \pm 8,3$ & $67,8 \pm 8,7$ & 0,226 & $70,3 \pm 8,6$ \\
\hline $\begin{array}{l}\text { Erkek } \\
\text { cinsiyet }\end{array}$ & $29(\% 93,5)$ & $18(\% 94,7)$ & 0,864 & $47(\% 94)$ \\
\hline $\begin{array}{l}\text { Anevrizma } \\
\text { çapı (cm) }\end{array}$ & $6,69 \pm 1,27$ & $7,26 \pm 1,84$ & 0,432 & $6,9 \pm 1.5$ \\
\hline DM & $7(\% 22,6)$ & $1(\% 5,3)$ & 0,105 & $8(\% 16)$ \\
\hline HT & $19(\% 61,3)$ & $8(\% 42,1)$ & 0,186 & $27(\% 54)$ \\
\hline $\begin{array}{l}\text { Sigara } \\
\text { kullanımı }\end{array}$ & $12(\% 38,7)$ & $7(\% 36,8)$ & 0,895 & $19(\% 38)$ \\
\hline KAH & $15(\% 48,4)$ & $7(\% 36,8)$ & 0,425 & $22(\% 44)$ \\
\hline KBY & $5(\% 16,1)$ & $1(\% 5,3)$ & 0,251 & $6(\% 12)$ \\
\hline Karın ağrısı & $25(\% 80,6)$ & $13(\% 68,4)$ & 0,326 & $38(\% 76)$ \\
\hline
\end{tabular}

DM: diabetes mellitus, HT: hipertansiyon, $\mathrm{KAH}$ : koroner arter hastalığı, KBY: kronik böbrek yetmezliği.

\section{Postoperatif Veriler}

Hastanede yatış süresi, EVAR grubunda ortalama $13,1 \pm 6,1$ gün, açık cerrahi grubunda ortalama $18,7 \pm 9$ gün, toplamda ise ortalama 15,2 $\pm 7,7$ gün olarak saptand1. Yoğun bakımda kalış süresi, EVAR grubunda ortalama 1,9 $\pm 2,6$ gün, açık cerrahi grubunda ortalama $3,2 \pm 4,4$ gün, toplamda ise ortalama $2,4 \pm 3,4$ gün olarak tespit edildi. Operasyon sırasında ve postoperatif dönemde hasta için kullanılan kan transfüzyonu miktarı, EVAR grubunda ortalama 2,4 $\pm 3,1$ ünite, açık cerrahi grubunda ortalama $6,1 \pm 5,3$ ünite, toplamda ise $3,7 \pm 4,4$ ünite olarak saptandi. Postoperatif komplikasyonlar EVAR grubunda $3(\% 9,7)$ hastada, açık cerrahi grubunda $2(\% 10,5)$ hastada, toplamda ise 5 (\%10) hastada saptandi. EVAR grubundaki toplam 3 hastanın birinde $\mathrm{ABY}$, diğerinde $\mathrm{AF}$, ötekisinde ise $\mathrm{AF}$ ve $\mathrm{MI}$ gelişen postoperatif komplikasyonlardı. Açık cerrahi grubunda 2 hastada pnömoni gelişti. Mortalite EVAR grubunda $2(\% 6,4)$ hastada görüldü, açık cerrahi grubunda ise hiçbir hastada görülmemiş olup toplamda 2 (\% 4) hastada saptanmış oldu.

EVAR ve açık cerrahi uygulanan gruplar karşılaştırıldığında, komplikasyon ve mortalite bakımından anlamlı fark bulunmamıştır ( $p>0,05)$. Ancak, hastaların hastanede ve yoğun bakımda yatış süreleri ile hastalara yapılan kan transfüzyonu miktarı karşılaştırıldığında istatistiksel olarak anlamlı fark saptanmış olup her üç parametre için de EVAR üstün bulunmuştur $(\mathrm{p}<0,05$, Tablo II).

Tablo II. Postoperatif veriler

\begin{tabular}{|l|c|c|c|c|}
\hline & $\begin{array}{c}\text { EVAR } \\
(n=31)\end{array}$ & $\begin{array}{c}\text { Açık cerrahi } \\
(n=19)\end{array}$ & $\begin{array}{c}\text { P } \\
\text { değeri }\end{array}$ & $\begin{array}{c}\text { Toplam } \\
(n=50)\end{array}$ \\
\hline $\begin{array}{l}\text { Hastanede } \\
\text { ortalama yatış } \\
\text { süresi (gün) }\end{array}$ & $13,1 \pm 6,1$ & $18,7 \pm 9$ & $0,02^{*}$ & $15,2 \pm 7,7$ \\
\hline $\begin{array}{l}\text { Yoğun } \\
\text { bakımda } \\
\text { ortalama yatış } \\
\text { süresi (gün) }\end{array}$ & $1,9 \pm 2,6$ & $3,2 \pm 4,4$ & $0,002^{*}$ & $2,4 \pm 3,4$ \\
\hline $\begin{array}{l}\text { Kan transfüz- } \\
\text { yonu (ünite) }\end{array}$ & $2,4 \pm 3,1$ & $6,1 \pm 5,1$ & $0,003^{*}$ & $3,7 \pm 4,4$ \\
\hline Komplikasyon & $3(\% 9,7)$ & $2(\% 10,5)$ & 0,923 & $5(\% 10)$ \\
\hline Mortalite & $2(\% 6,4)$ & $0(\% 0)$ & 0,258 & $2(\% 4)$ \\
\hline *: p<0,05 & & & & \\
\hline
\end{tabular}

\section{Tartışma ve Sonuç}

AAA prevelansı 55-60 yaş aralığından önce düşük olup bu dönemden sonra yaş ile birlikte artmaya baş$\operatorname{lar}^{10}$. Bizim araştırmamızda hastaların ortalama yaşı $70,3 \pm 8,6$ saptand1. Erkeklerde daha siktır ve prevalans 65 yaşındaki kadınlarda \%0,43 iken 75 yaşındaki erkeklerde \%1,15 saptanmıştır ${ }^{11}$. Bizim araştırmamızda 47 (\%94) hasta erkek idi.

KAH ve HT AAA gelişimi için risk faktörüdür ${ }^{12}$. Bizim araştırmamızda 27 (\%54) hastada HT ve 22 (\%44) hastada KAH mevcut idi. AAA için en güçlü bağımsız risk faktörü elastin yıkımına da neden olan sigaradır $^{13}$. Araştırmamızda sigara kullanan hasta sayıs 19 (\%38) idi. İlginç olarak DM’si bulunanlarda AAA gelişmesi riski, DM'si bulunmayanlara göre daha düşük saptanmıştır ${ }^{14}$. Araştırmamızda 8 (\%16) hastada DM mevcut idi.

Hastalar farklı semptomlardan yakınabilir, asemptomatik olabilir ya da şok veya senkop ile başvurabilirler. AAA'sı olan hastalarda karın ağrısı, pulsatil kitle ve hipotansiyon hastaların \%50'sinde bulunur. Bizim araştırmamızda $38(\% 76)$ hastada karın ağrısı mevcut idi.

Fizik muayene ile; hastaların neredeyse yarısına tanı koyulabilmesine rağmen radyolojik olarak gösterilmiş AAA'sı bulunan hastaların 1/3'ünden fazlasının tespit edilemediği saptanmıştır ${ }^{15}$. AAA'ların saptanmasında USG ilk düşünülmesi gereken görüntüleme yöntemi olup yüksek özgüllük ve duyarlılık oranına sahiptir ${ }^{16}$. Mortalite oranının azaltılmasında en kolay ve ucuz yolun tarama olduğu kanıtlanmıştır ve anevrizma 


\section{G. Çitoğlu ve E. Dayığlu}

taramasının rüptür insidansını azalttığı gösterilmiștir ${ }^{17}$. Rüptür insidansı anevrizma çapının artması ile yükselir ve yıllık rüptür oranı anevrizma çap $1>5,5 \mathrm{~cm}$ olanlarda \%5,3'tür ${ }^{18}$. Bizim araştırmamızda hastaların anevrizma çapı ortalama $6,9 \pm 1,5 \mathrm{~cm}$ idi.

AAA tamiri sonrası oluşan komplikasyonların geç fark edilmesi ve bunlara geç müdahalede bulunulması postoperatif mortalitenin ana nedenlerindendir ${ }^{19}$. Araştırmamızda EVAR grubunda toplamda $3(\% 9,7)$ hastada komplikasyon gelişmiştir. Bu hastaların birinde $A F$ ve $M I$, diğerinde $A B Y$ ve ötekisinde ise $A F$ gelişmiştir. Açık cerrahi grubunda ise $2(\% 10,5)$ hastada komplikasyon gelişmiş olup bu komplikasyon pnömonidir. Araştırmamızda EVAR ve açık cerrahi grubunun karşılaştırırsak, istatistiksel olarak anlamlı fark yoktur $(\mathrm{p}=0,923)$.

Operatif mortalite açık cerrahide \%4,6 iken EVAR'da \%1,2' $\mathrm{dir}^{20}$. AAA tamirinden sonra ortalama sağkalım süresi ise 9 yıldır $^{21}$. Bizim araştırmamızda açık cerrahi grubunda mortalite saptanmamıştır. EVAR grubunda ise $2(\% 6,4)$ hasta ex olmuştur. Araştırmamızda mortalite açısından EVAR ve açık cerrahi grubu arasında anlamlı fark saptanmamıştır $(p=0,162)$. Ex olan hastaların bir tanesinde HT, periferik arter hastalığı, KAH, SVH (serebrovasküler hastalık) mevcuttu ve hasta sigara içicisiydi. Bu hastada operasyon sonrası AF saptanmış olup, takiben postoperatif 5.günde gelişen akut MI sonrası hastaya acil koroner anjiografi yapılmış ve sol ön inen koroner artere stent implantasyonu gerçekleştirilmiştir. Fakat hasta postoperatif 11. gün kalp yetmezliği nedeniyle kaybedilmiştir. Ex olan diğer hastada ise HT, SVH, DM ve KAH mevcuttu, ayrıca hasta sigara içicisiydi. Bu hastada operasyon sonrası ABY gelişmiş ve hasta postoperatif 13. gün yine kardiyak nedenle kaybedilmiştir. KAH non-kardiyak cerrahi sonrası ilk 30 günde görülen ölümlerin $\% 40$ 'ından fazlasından sorumludur ${ }^{22}$. AAA tamiri sonrası 30 gün içinde kardiyak nedenlere bağl1 ölüm ya da MI açısından açık cerrahide risk oranı $\geq \% 5$ olup bu oran EVAR'da ise \%1-5 aralığında olduğundan kardiyak açıdan açık cerrahi yüksek riskli EVAR ise orta riskli girişim olarak sınıflandırılmıştır ${ }^{23}$. Literatürde, EVAR'1 ve açık cerrahiyi karşılaştıran birçok araştırma mevcuttur, bunların başlıcalarına değinecek olursak:

DREAM $^{20}$ : Araştırmada 345 hasta mevcuttur ve hasta takip süresi 30 gündür. Operasyon süresi, kan kaybı miktarı, kan transfüzyonu miktarı, yoğun bakımda kalış süresi, postoperatif mekanik ventilasyon süresi, hastanede kalış süresi ve komplikasyon oranı bak1mından EVAR üstün saptanmıştır. Daha sonra araştırmanın 12-15 yıllık sonuçları yayımlanmıştır ve tekrar girişim oranı EVAR sonrası \%34,9 açık cerrahi sonrası ise \%13,6 saptanmıştır ${ }^{24}$. EVAR $1^{25}$ : Araştırma 1082 hastayı kapsamakta olup 30 günlük sonuçlar sunulmuştur. Mortalite, hastanede kalış süresi ve operasyon süresi yönünden EVAR üstün bulunmuştur fakat tekrar girişim oranı EVAR'da daha yüksek saptanmıştır. Sonrasında araştırmanın 15 yıllık sonuçları yayımlanmıştır ve tekrar girişim oranı EVAR sonrasında yine daha yüksek bulunmuştur, ayrıca 8. yıldan sonra mortalite yönünden açık cerrahi üstün saptanmıştır ${ }^{26}$. OVER ${ }^{27}$ : 881 hasta incelenmiştir ve hasta takip süresi 2 yılı bulmaktadır. Girişim sonrasındaki 30 günde mortalite, operasyon süresi, kan kaybı, kan transfüzyonu, mekanik ventilasyon süresi, kladikasyo, hastanede ve yoğun bakımda kalış süresi açısından EVAR üstün bulunmuştur. Daha sonra araştırmanın 9 yıla ulaşan sonuçları sunulmuştur; mortalite açısından EVAR'ın üstünlüğünü ancak ilk 3 yıl koruyabildiği, ayrıca EVAR sonrası anevrizma rüptürlerinin saptandığı açıklanmıştır ${ }^{28}$. Sağkalım açısından beklenenin aksine; 70 yaşın altındaki hastalarda EVAR, 70 yaşın üzerindeki hastalarda ise açık cerrahi üstünlük sağlamıştır ${ }^{28}$. ACE ${ }^{29}$ : Araştırmada 299 hasta analiz edilmiş olup hastalar 5 yıla varan süre ile takip edilmiştir. Erken dönemde operasyon süresi, mekanik ventilasyon süresi, kan transfüzyonu, hastanede kalış süresi açısından EVAR üstün bulunmuştur. Uzun dönemde ise tekrar girişim ve kladikasyo oranı EVAR'da daha yüksek saptanmıştır. Kesi yeri komplikasyonları açık cerrahide daha yüksek oranda bulunmuştur.

Bizim araştırmamızda EVAR; yoğun bakımda yatış süresi $(p=0,002)$, hastanede yatış süresi $(p=0,02)$ ve kan transfüzyonu miktarı $(\mathrm{p}=0,003)$ bakımından istatistiksel açıdan anlamlı olacak şekilde üstün bulunmuştur. Değindiğimiz başlıca araştırmalar da sonuçlarımızı destekler niteliktedir. Tüm bu araştırmalar 1ş1ğında şunu söyleyebiliriz ki; EVAR'ın ve açık cerrahinin erken dönem sonuçları karşılaştırıldığında, hastanede kalış süresini azaltması ve tedavinin morbiditesini ve mortalitesini düşürmesi nedeniyle EVAR üstündür. Fakat zamandan bağımsız olarak; tekrar girişim ve postoperatif rüptür riski açısından, açık cerrahi EVAR'dan daha iyi sonuçlar sağlamıştır. Erken dönemde EVAR'ın göreceli olarak daha düşük olan mortalite oranı, ilerleyen zamanlarda sürdürülememiş olup uzun dönemde açık cerrahi ve EVAR grubundaki hastaların mortalite oranları arasında anlamlı fark saptanmamıştır. Ayrıca uygun olmayan anatomik özellikler varlığında yapılacak EVAR; başarısız sonuç, açık cerrahiye dönüş ve anevrizma rüptürü riskini artırır. EVAR sonrası tekrar girişim olasılığı dikkate alınarak, özellikle açık cerrahinin riskini artıracak yandaş faktörlerin ve hastalıkların eşlik ettiği yüksek riskli hastalarda, eğer anatomik kriterler uygunsa EVAR tercih edilmelidir.

\section{Kaynaklar}

1. Kent KC. Clinical practice. Abdominal aortic aneurysms. N Engl J Med. 2014; 371(22): 2101-8. 


\section{Abdominal Aort Anevrizmalarının Tamir Sonuçları}

2. Kuivaniemi H, Ryer EJ, Elmore JR, Tromp G. Understanding the pathogenesis of abdominal aortic aneurysms. Expert Rev Cardiovasc Ther. 2015; 13(9): 975-87.

3. Jacomelli J, Summers L, Stevenson A, Lees T, Earnshaw JJ. Impact of the first 5 years of a national abdominal aortic aneurysm screening programme. Br J Surg. 2016;103(9): 1125-31.

4. Lederle FA, Johnson GR, Wilson SE, Ballard DJ, Jordan WD Jr, Blebea J, Littooy FN, Freischlag JA,Bandyk D, Rapp JH, Salam AA; Veterans Affairs Cooperative Study \#417 Investigators. Rupture rate of large abdominal aortic aneurysms in patients refusing or unfit for elective repair. JAMA. 2002; 287(22): 2968-72.

5. Chaikof EL, Blankensteijn JD, Harris PL, White GH, Zarins CK, Bernhard VM, Matsumura JS, May J,Veith FJ, Fillinger MF, Rutherford RB, Kent KC; Ad Hoc Committee for Standardized Reporting Practices in Vascular Surgery of The Society for Vascular Surgery/American Association for Vascular Surgery. Reporting standards for endovascular aortic aneurysm repair. J Vasc Surg. 2002;35(5): 1048-60.

6. Wanhainen A, Verzini F, Van Herzeele I, Allaire E, Bown M, Cohnert T, Dick F, van Herwaarden J, Karkos C, Koelemay M, Kölbel T, Loftus I, Mani K, Melissano G, Powel J, Szeberin Z, Esvs GuidelinesCommittee, de Borst GJ, Chakfe N, Debus S, Hinchliffe R, Kakkos S, Koncar I, Kolh $\mathrm{P}$, Lindholt JS, de Vega M, Vermassen F, Document Reviewers, Björck M, Cheng S, Dalman R, Davidovic L, Donas K,Earnshaw J, Eckstein HH, Golledge J, Haulon S, Mastracci T, Naylor R, Ricco JB, Verhagen H. European Society for Vascular Surgery (ESVS) 2019 Clinical Practice Guidelines on the Management of Abdominal Aorto-iliac Artery Aneurysms. Eur J Vasc Endovasc Surg. 2019; 57(1): 8-93.

7. White GH, May J, Waugh RC, Chaufour X, Yu W. Type III and type IV endoleak: toward a complete definition of blood flow in the sac after endoluminal AAA repair. J Endovasc Surg. 1998;5(4): 305-9.

8. Lal BK, Zhou W, Li Z, Kyriakides T, Matsumura J, Lederle FA, Freischlag J; OVER Veterans Affairs Cooperative Study Group. Predictors and outcomes of endoleaks in the Veterans Affairs Open Versus Endovascular Repair (OVER) Trial of Abdominal Aortic Aneurysms. J Vasc Surg. 2015; 62(6): 1394 404.

9. Ma B, Wang YN, Chen KY, Zhang Y, Pan H, Yang K. Transperitoneal versus retroperitoneal approach for elective open abdominal aortic aneurysm repair. Cochrane Database Syst Rev. 2016; 2: CD010373.

10. Sampson UK, Norman PE, Fowkes FG, Aboyans V, Song Y, Harrell FE Jr, Forouzanfar MH, Naghavi M, Denenberg JO, McDermott MM, Criqui MH, Mensah GA, Ezzati M, Murray C. Estimation of global and regional incidence and prevalence of abdominal aortic aneurysms 1990 to 2010. Glob Heart. 2014; 9(1): 159-70.

11. Thompson SG, Bown MJ, Glover MJ, Jones E, Masconi KL, Michaels JA, Powell JT, Ulug P,Sweeting MJ. Screening women aged 65 years or over for abdominal aortic aneurysm: a modelling study and health economic evaluation. Health Technol Assess. 2018; 22(43): 1-142.

12. Svensjö S, Björck M, Gürtelschmid M, Djavani Gidlund K, Hellberg A, Wanhainen A. Low prevalence of abdominal aortic aneurysm among 65-year-old Swedish men indicates a change in the epidemiology of the disease. Circulation. 2011; 124(10): 1118-23.

13. Lederle F, Johnson GR, Wilson SE, Chute EP, Hye RJ, Makaroun MS, Barone GW, Bandyk D, Moneta GL, Makhoul RG. The aneurysm detection and management study screening program: validation cohort and final results. Aneurysm Detection and Management Veterans Affairs Cooperative Study Investigators. Arch Intern Med. 2000; 160(10): 1425-30.

14. Lederle FA. The strange relationship between diabetes and abdominal aortic aneurysm. Eur J Vasc Endovasc Surg. 2012; 43(3): 254-6.

15. Karkos CD, Mukhopadhyay U, Papakostas I, Ghosh J, Thomson GJ, Hughes R. Abdominal aortic aneurysm: the role of clinical examination and opportunistic detection. Eur J Vasc Endovasc Surg. 2000; 19(3): 299-303.

16. Lindholt JS, Vammen S, Juul S, Henneberg EW, Fasting H. The validity of ultrasonographic scanning as screening method for abdominal aortic aneurysm. Eur J Vasc Endovasc Surg. 1999; 17(6): 472-5.

17. Lindholt JS, Sogaard R. Population screening and intervention for vascular disease inDanish men (VIVA): a randomised controlled trial. Lancet. 2017; 390(10109): 2256-2265.

18. Parkinson F, Ferguson S, Lewis P, Williams IM, Twine CP; South East Wales Vascular Network. Rupture rates of untreated large abdominal aortic aneurysms in patients unfit for elective repair. J Vasc Surg. 2015; 61(6): 1606-12.

19. Waits SA, Sheetz KH, Campbell DA, Ghaferi AA, Englesbe MJ, Eliason JL, Henke PK. Failure to rescue and mortality following repair of abdominal aortic aneurysm. J Vasc Surg. 2014; 59(4): 909-914.

20. Prinssen M, Verhoeven EL, Buth J, Cuypers PW, van Sambeek MR, Balm R, Buskens E, Grobbee DE,Blankensteijn JD; Dutch Randomized Endovascular Aneurysm Management (DREAM) Trial Group. A randomized trial comparing conventional and endovascular repair of abdominal aortic aneurysms. N Engl J Med. 2004; 351(16):1607-18.

21. Mani K, Björck M, Lundkvist J, Wanhainen A. Improved longterm survival after abdominal aortic aneurysm repair. Circulation. 2009; 120(3): 201-11.

22. Vascular Events In Noncardiac Surgery Patients Cohort Evaluation (VISION) Study Investigators,Devereaux PJ, Chan MT, Alonso-Coello P, Walsh M, Berwanger O, Villar JC, Wang CY, Garutti RI, Jacka MJ, Sigamani A, Srinathan S, Biccard BM, Chow CK, Abraham V, Tiboni M, Pettit S, Szczeklik W, Lurati Buse G, Botto F, Guyatt G, HeelsAnsdell D, Sessler DI, Thorlund K, Garg AX, Mrkobrada M, Thomas S, Rodseth RN, Pearse RM, Thabane L, McQueen MJ, VanHelder T, Bhandari M, Bosch J, Kurz A,Polanczyk C, Malaga G, Nagele P, Le Manach Y, Leuwer M, Yusuf S. Association between postoperative troponin levels and 30-day mortality among patients undergoing noncardiac surgery. JAMA. 2012; 307(21): 2295-304.

23. Kristensen SD, Knuuti J, Saraste A, Anker S, Bøtker HE, Hert SD, Ford I, Gonzalez-Juanatey JR, Gorenek B, Heyndrickx GR, Hoeft A, Huber K, Iung B, Kjeldsen KP, Longrois D, Lüscher TF, Pierard L, Pocock S,Price S, Roffi M, Sirnes PA, Sousa-Uva M, Voudris V, Funck-Brentano C; Authors/Task Force Members. 2014 ESC/ESA Guidelines on noncardiac surgery: cardiovascular assessment and management: The Joint Task Force on non-cardiac surgery: cardiovascular assessment and management of the European Society of Cardiology (ESC) and the European Society of Anaesthesiology (ESA). Eur Heart J. 2014; 35(35): 2383-431.

24. Blankensteijn, de Bruin J, Grobbee R, Prinssen M, van Sambeek M, van Schaik TG, et al. Very long-term follow-up (12-15 Years) of the Dutch randomized endovascular aneurysm repair management (DREAM) trial. J Vasc Surg. 2016; 63(6): $143 \mathrm{~S}$.

25. Greenhalgh RM, Brown LC, Kwong GP, Powell JT, Thompson SG, EVAR trial participants. Comparison of endovascular aneurysm repair with open repair in patients with abdominal aortic aneurysm (EVAR trial 1), 30-day operative mortality results: randomised controlled trial. Lancet 2004; 364(9437): 843-8.

26. Patel R, Sweeting MJ, Powell JT, Greenhalgh RM, EVAR trial investigators. Endovascular versus open repair of abdominal aortic aneurysm in 15-years' follow-up of the UK endovascular 


\section{G. Çitoğlu ve E. Dayıoğlu}

aneurysm repair trial 1 (EVAR trial 1): a randomised controlled trial. Lancet 2016; 388(10058): 2366-74.

27. Lederle FA, Freischlag JA, Kyriakides TC, Padberg FT Jr, Matsumura JS, Kohler TR, Lin PH, Jean-Claude JM, Cikri DF, Swanson KM, Peduzzi PN; Open Versus Endovascular Repair (OVER) Veterans Affairs Cooperative Study Group. Outcomes following endovascular vs open repair of abdominal aortic aneurysm: a randomized trial. JAMA. 2009; 302(14): 1535-42.
28. Lederle FA, Freischlag JA, Kyriakides TC, Matsumura JS, Padberg FT Jr, Kohler TR, Kougias P, Jean-Claude JM, Cikrit DF, Swanson KM; OVER Veterans Affairs Cooperative Study Group. Long-term comparison of endovascular and open repair of abdominal aortic aneurysm. N Engl J Med. 2012; 367 (21): 1988-97.

29. Becquemin JP, Pillet JC, Lescalie F, Sapoval M, Goueffic Y, Lermusiaux P, Steinmetz E, Marzelle J; ACE trialists. A randomized controlled trial of endovascular aneurysm repair versus open surgery for abdominal aortic aneurysms in low-to moderate-risk patients. J Vasc Surg. 2011; 53(5): 1167-73. 